\title{
The Meaning of Application of the Medical Education Accreditation in China
}

\author{
Na Wang \\ Department of Anesthesiology \\ The Hospital of Jilin University \\ Changchun, China \\ wangna080613@163.com
}

\author{
Corresponding author: Jinguo Wang* \\ Department of Urology \\ The First Hospital of Jilin University \\ Changchun, China \\ wangjinguolily@163.com
}

\begin{abstract}
Medical education accreditation is an external audit mechanism of the quality of medical education and its theory and practice have been widely recognized. Our country tried to implement medical education accreditation by strengthening the international and regional cooperation, developing related training program, establishing the accreditation system and establishing an information database. Due to differences in the knowledge, resources and political guidance in different regions, Medical education accreditation remains to be further standardized.
\end{abstract}

Keywords—medical education accreditation; medical education; quality assurance

\section{INTRODUCTION}

The beginning of the 21st century new problems appeared in the field of medicine, highlighting the failure of equitable sharing health achievements, a new type of medical risk, environment risk, risk behavior is threatening the health of human beings in the world, medical safety has become the basic characteristics of modern medicine and the quality connotation, is also continuous efforts and struggle, but the crisis rather than be curbed, instead of increased year by year. Visible, global health systems are gradually complicated, thus puts forward new requirements to the medical and health personnel training.

Transformation is the modern medical education is a very important characteristic, also is the urgent task facing the contemporary medical education, it is imperative that clinical medical education curriculum integration, integration of a wide range of medical courses, with the integration of medical and other natural science, with a medical professional with the medical course integration, with a medical professional course internal integration, therefore, medical education must break the isolated situation of the medical profession, coordinate with each other for medical education and medical science development and promote the development of the internationalization of higher medical education [1].

\section{MEdiCAl EdUCATION ACCREDITATION}

\section{A. The Conception of Medical Education Accreditation}

Internationalization of medical education, medical human resources of transnational and trans-regional flow increasing tendency, makes the medical education quality security problems become the focus of global attention. According to the foundation for the promotion of international medical education and research establish the database of international medical education directory to the latest statistics. These different corner of the world of medicine distribution in culture and education tradition, management system, curriculum, teaching methods, evaluation methods, available resources, clinical practice displays diverse characteristics, how to different countries and the area of medical colleges education quality, ability and quality of medical talent cultivation by appropriate evaluation is a pretty big problem, because both must consider the local resources and needs, and universally applicable evaluation principles [2].

Medical education certification as a kind of external quality auditing mechanism is considered to be the effective way to solve this problem, conduce to improving the quality of medical education, to ensure the safety of medical services and the rational use of medical talents [3]

Certification is made by designated specialized agencies adopt a set of clear standards and procedures for review and evaluation process of education institutions. Among them, the certification standards, certification procedures and certification bodies are indispensable three elements. Ideally, certification bodies should be independent, nonprofit, nongovernmental entities, certification should be also voluntarily rather than by the laws or regulations to enforce, but around the world medical education certification status, more than half of the certification is set up by the government to enforce the certification body.

Accreditation standards as a yardstick to measure the quality of medical education, medical education certification standard covers the whole process of each link (training objectives, curriculum setting, education resources and teaching staff, education management and future development planning, etc.), but the establishment of standard does not mean that draw a strict education plan and education content, but to admit that between regions and countries, respect the differences between the characteristics of each medical schools and different development status and respect its reasonable autonomy as the objective, so education institutions under the general principle has enough space and freedom to show their own characteristics [4].

At the same time, to encourage education institutions to continuous improvement, international standards set not only 
the most basic requirement, also to go beyond basic standards established by reference to the quality of development. It is widely recognized by various countries and various areas all over the World medical Education standards is the World medical Education association published in 2001, "international standard of undergraduate medical Education", this has become a regional or national standard templates, have been translated into many languages, many countries has carried on the revision of the localization [5].

\section{General Practitioner Training AND MEDiCAL EDUCATION ACCREDITATION ABROAD}

\section{A. The Training of General Practitioner and Medical} Education Accreditation in America

The first is in the United States after four years of medical preparation, and then into the medical colleges to study medical doctor's degree for 4 years, and then apply to the training program hospital and get consent for three years of residency training in general medicine. General practitioner training programs with an emphasis on clinical skills training focuses on cultivating the ability to solve the problem of common health community [6]. Attend the exam of family physician association after training, to pass the exam after winning family physician qualification certificate, before opening, practicing medicine. After opening and continuing medical education program, requires every three years to 150 credits, every 6 years needed to certification.

\section{B. The Training of General Practitioner and Medical Education Accreditation in Britain}

In Britain, the medical students of undergraduate course graduation must choose the three-year training after graduation project in general medicine. Met the requirement of the end of the study, and through the specialized subject to examination, can get graduation certificate and GP specialized subject to membership. Because of the training is very strict, very few people pass the examination for training certificate. Therefore, the British GP training is the elite in the medical students.

\section{The Training of General Practitioner and Medical Education Accreditation in Germany}

German medical education at the university of year is 6 years. Want to become a general practitioner medical professional college graduates, there must be a process of specialization. This system began in 1968, specialization of 2 3 years, has been increased to 1998 for five years. Mainly pay attention to training the following 6 kinds of skills: primary health care management, people-centered care, solve common health problems, comprehensive diagnosis and treatment method, community oriented service, the overall medical diagnosis model [7]. After examination was general practitioner's qualification certificate is allowed to open in the community. In addition, Germany pays attention to GP to continue education, a monthly average of 17.6 hours for continuing medical education training.

\section{ENLIGHTENMENT OF MEDICAL EDUCATION ACCREDITATION IN OUR COUNTRY}

\section{A. Medical Education Accreditation of Undergraduate Education}

In recent years, the domestic some medical colleges and universities began to set up the general medicine, or courses in general medicine. In the clinical medical professional colleges and universities, according to the teaching process, the corresponding teaching task at the same time, might as well add related theory course in general medicine, such as introduction to general medicine and community health service management, community common health problems such as curriculum, and as an elective or required courses, it make the medical students to understand ideas in general medicine, content and methods of general practitioners work task and become a general practitioner or specialist for the future lay the foundation with GPS communication and coordination. In the clinical departments to rotate at the same time, the other additional communities of practice, in-depth community to develop community health service medical treatment, disease prevention, rehabilitation and education activities, cultivate and improve the ability of community health service [8].

\section{B. Medical Education Accreditation of Graduate Education}

For most not second-degree subject setting of master's in general medicine colleges and universities, might as well in the examination for clinical medicine and preventive medicine graduate students, on the premise of fully respect students individual desire, will be part of the students determine the direction in general medicine, on general medicine related theoretical research and practical exploration, constantly improve the level of academic research in general medicine, provide theoretical basis and practical guidance for general medicine development.

\section{Medical Education Accreditation for the Training of General Practitioner}

General medical education after graduation After graduating from standardized training in general medicine is the core of general practice medical education system, colleges and universities students of medical major undergraduate course graduation, has been standardized training in general medicine, can get GPS standardization training certificate. In order to improve the quality of the training, should be general practitioners standardized training model and standard, the standard of the training base and management methods, relying on the best medical colleges [9].

\section{Application of MEdicAl EdUCATION ACCREDitATION TO OUR COUNTRY}

\section{A. Teaching Reform for Medical Education Accreditation}

Translational medicine study has broad prospects for development, to the prospective research target in patients, emphasized disease early detection and evaluation, and to urge medical staff on the basis of the research, the results of transformation and application of conducting at the same time, make the results applied to clinical, according to the clinical effect of deep research, the development once the two-way channels open, will be the promotion of basic research results 
quickly service for clinical medicine, public health for disease control and prevention and improvement and the government policy. According to China's national conditions, the current could quickly put some mature biotechnology and the basis of the results into patients and the general public health tool, is the direction of the transformation of the current medical education development.

\section{B. Medical Education Accreditation Guides Subject Construction}

Discipline is the foundation of medical education, is the lifeline of medical colleges and universities based on and development of subject construction, the construction level directly reflects the school education level and academic status, here to translational medicine guidance is particularly important in discipline construction. Especially with the transformation of medical model, the relationship between various disciplines increasingly close, no major breakthrough of research projects, all need much discipline, much professional collaboration, so more should be guided by the clinical discipline construction, integrating multidisciplinary knowledge, go the way of open joint. Advocating deep clinical medical students, graduate students, the basic research achievements applied in clinical practice.

\section{Adapt the Teaching Contents and Methods to the Medical Education Accreditation}

Higher medical education in China in the 21st century must be established to adapt to social development, to adapt to the international development trend of talent training mode, its goal is to cultivate a solid, high quality and creative ability, the modernization of medical talents. Education theory research and practice is a core concept in the training objectives, it is to make the medical students as a kind of what kind of people expected and specified. In the world today, in the period of unprecedented education reform of our country's education policy, social demand, and the characteristics of the medical education and great changes have taken place. Along with the social, psychological and environment is the integration of many factors, such as changes in medical model, medical students' training objectives should be free from pure biomedical and treatment model, the framework of the doctor into the active participation of doctor-patient interaction between medical service mode, education goals cannot be limited to cultivate medical students with professional knowledge, should be extended to develop medical thinking and medical moral of medical students. Review medical education that would become clear, separated from the clinical practice of medical colleges, medical education in clinical medicine, medical education for clinical medical service all the time, but now medical education from clinical signs, so education should return to clinical, and to clinical [10]. With the rapid development of modern medicine, medical impersonal trend also produced more and more, the current medical technology alienation is one of the medical crisis of modernity cannot ignore the objective factors, science of infinite expansion at the same time make the humanities gradually marginalized. However, medicine can not live without technology, we can't stop should not stop technology development. At present, the moral conscience was drugged rather than be removed or completely abandoned, we can only hope that the technology reshapes the humanized concept and teaching which will be effective method applied to individual patients, scientific knowledge is one of the two tasks of medical education reform is urgently needed.

\section{SUMMARY}

New century education reform focus on competence based curriculum, emphasize team based across professional education, pay more attention to, which is based on information technology in the teaching and management skills, the ultimate goal is to eliminate the differences between hard, medical education certification means that pure science foundation model has not adapt to the development of modern medical education, must be combined with social medicine and science and technology, change the original old medical education pattern, make it adapt to the medical education certification, the development of modern medical science and medical education needs.

\section{REFERENCES}

[1] Shin J, Milton S. The effects of performance budgeting and funding programs on graduation rate in public four-year colleges and universities. Educational Policy. 2007

[2] John W, George D, Peterson L. Quality Assurance of Engineering Education through Accreditation: The Impact of Engineering Criteria 2000 and Its Global influence. Journal of Engineering Education. 2005

[3] Bertalanffy L von. General System Theory: Foundations, Development, Applications. 1973

[4] Tyler RW. Basic Principles of Curriculum and Instruction. . 1950

[5] Baumol WJ, Benhabib J. Chaos: Significance, Mechanism, and Economic Applications. Journal of Econometrics. 1989

[6] Altbach PG, Bedahl RO, Gumport PJ. American Higher Education in the Twenty-First Century: Social, Political, and Economic Challenges. 1999

[7] Martin Heidegger. Poetry, Language, Thought. 1999

[8] Bogue EG. Twenty years of performance funding in Tennessee: A case study of policy intent and effectiveness. Funding public colleges and universities: popularity, problems, and prospects. 2002

[9] Judith S Eaton. An Overview of U.S. Accreditation. http://www.chea.org/pdf/2009.06_O verview_of_US_Accreditation.pdf. 2009

[10] Jerry E Trapnell. AACSB International accreditation: the value proposition and a look to the future. Journal of Management Development. 2007 